\title{
Manufaktur dan Uji Kinerja Proses Vacuum Forming Untuk Bahan Polymethyl Methacrylate (PMMA)
}

\author{
(Manufacture and Performance Test of Portable Vacuum Forming Machine for PMMA) \\ Cepi Rahmatullah Permana ${ }^{a}$, Cahyo Budiantoro ${ }^{b}$, Bayu Prabandono ${ }^{c}$ \\ ${ }^{a, b}$ Program Studi Teknik Mesin, Fakultas Teknik, Universitas Muhammadiyah Yogyakarta \\ JI, Brawijaya, Kasihan, Bantul, Yogyakarta - 55183. \\ e-mail: cepirahmatullah@gmail.com, cahyo_budi@umy.ac.id \\ 'Program Studi Teknik Mesin, Politeknik ATMI Surakarta \\ JI Adisucipto/JI Mojo No 1 PO BOX 215 Surakarta \\ e-mail: bayu_prabandono@atmi.ac.id
}

\begin{abstract}
Abstrak
Mesin pembuat kemasan yang sederhana dan murah dengan kinerja yang memadai diperlukan untuk meningkatkan nilai ekonomis produk industri rumah tangga (UKM). Penelitian ini bertujuan untuk membuat dan menguji kinerja mesin vakum forming pada bahan Polymethylmetacrylate (PMMA).Tahapan dalam pembuatan mesin ini adalah studi rancangan, manufaktur bagian mesin, cetakan, perakitan dan uji coba kinerja. Cetakan dibuat dari bahan kayu jati berukuran $140 \mathrm{~mm} \times 210 \mathrm{~mm} \times 15 \mathrm{~mm}$. Pengujian kinerja mesin dilakukan dengan memanaskan lembaran plastik PMMA tebal $0.25 \mathrm{~mm}$ pada variasi waktu pemanasan 15, 20 dan 25 detik dan waktu vakum 5, 10 dan 15 detik, menggunakan pemanas 100 watt dan tekanan vakum maksimum $12 \mathrm{kPa}$. Dimensi dan geometri produk dibandingkan dengan cetakan dan dievaluasi dengan pengukuran linier serta pengamatan visual. Hasil pengujian menunjukkan bahwa kombinasi waktu pemanasan 15 detik dan waktu vakum 5 detik menghasilkan produk dengan radius yang besar pada bagian dasar. Kombinasi waktu pemanasan 20 detik dan waktu vakum 10 detik dapat memperkecil ukuran radius. Hasil cetakan yang mendekati bentuk cetakan diperoleh dengan parameter suhu pemanasan $105^{\circ} \mathrm{C}$, waktu pemanasan 25 detik dan waktu vakum 15 detik.
\end{abstract}

Kata Kunci: Vacuum forming, Polymethyl Methacrylate (PMMA), waktu pemanasan, waktu vakum

\section{Abstract}

A simple and inexpensive packaging machine with adequate performance is needed to increase economic added value of the smal scale industries. This study aims to manufacture and to evaluate the performance of customized vacuum forming machine on Polymethylmetacrylate (PMMA)I. Manufacturing of components and molds, assembly and performance testing have been carried out to build the machine. The mold was made of teak wood with the dimension of 140 $\mathrm{mm} \times 210 \mathrm{~mm} \times 15 \mathrm{~mm}$. Machine performance testing was done by heating a $0.25 \mathrm{~mm}$ thick PMMA sheet with heating time variation of 15, 20 and 25 second and vacuum time of 5,10 and 15 second, respectively. The heating power was 100 watts and the maximum vacuum pressure was $12 \mathrm{kPa}$. Product quality were compared with mold by linear measurements and visual observations. The processing parameter of 15 second heating time and 5 second vacuum time produced a specimen with a large radius at the bottom. The combination of 20 second heating time and 10 second vacuum time reduced the size of the radius. The best product can be obtained with a heating temperature of $105{ }^{\circ} \mathrm{C}$, heating time of 25 second and a vacuum time of 15 second.

Keywords: Vacuum forming, Polymethyl Methacrylate (PMMA), heating time, vacuum time 


\section{Pendahuluan}

Penggunaan produk plastik tidak bisa lepas dari kebutuhan manusia dalam kehidupan sehari-hari. Produk plastik banyak digunakan karena nilai ekonomis, fleksibel, ringan dan tidak mudah pecah mulai dari peralatan makan dan minum hingga kemasan [1]. Mahalnya harga mesin pembuat kemasan produk berbahan plastik yang beredar di pasaran saat ini belum bisa dijangkau oleh Industri Kecil dan Menengah (UKM). Dengan demikian perlu adanya mesin/alat yang murah dan bisa memberikan kemudahan dalam menghasilkan kemasan produk. Sehingga pelaku usaha dapat berinovasi dan berkreasi dalam pembuatan produk serta secara ekonomis meningkatkan nilai tambah dari produk tersebut.

Pembuatan kemasan dapat dilakukan dengan metode Thermoforming, suatu proses pembentukan lembaran plastik yang dimulai dengan memanaskan dan kemudian membentuk lembaran plastik untuk mendapatkan hasil dari bentuk yang diinginkan baik dengan cara memberikan vacuum (hisapan) atau pressure (tekanan) lembaran plastik terhadap cetakan (mold). Pada prinsipnya mekanisme thermoforming terbagi atas tiga jenis yaitu vacuum forming, pressure forming dan mechanical forming untuk mendapatkan hasil cetakan yang diinginkan. Dari ketiga metode tersebut, vacuum forming adalah metode yang paling sederhana. Menurut Hussain dkk [2], dalam proses ini lembaran plastik dipanaskan pada suhu tertentu dengan pemanas listrik. Bentuk produk dihasilkan dengan menerapkan kondisi vakum antara cetakan dan lembaran plastik. Faktor yang paling penting dalam proses ini adalah waktu siklus kerja secara total (cycle time) [3]. Komponen waktu yang membentuk cycle time adalah waktu vakum dan waktu pemanasan yang mengendalikan aliran pemanasan dan waktu pendinginan [4]. Beberapa aplikasi proses menggunakan pemanasan secara konveksi melalui udara panas namun metode yang lebih umum adalah radiasi infra merah. Ada beberapa jenis elemen pemanas yang tersedia di pasaran, misalnya plat pemanas dan quartz heater [5].

Indikator kualitas produk vacuum forming adalah sifat mekanis dan ketebalan yang seragam dari seluruh bagian produk. Permasalahan yang seringkali muncul adalah terbentuknya radius yang besar pada bagian sudut produk dan pengurangan ketebalan. Kondisi ini disebabkan terjadinya orientasi dua arah (biaxial orientation) yang berpengaruh terhadap perbedaan ketebalan dan perubahan sifat mekanis produk [6]. Suhu pelunakan bahan (glass transition temperature/Tg) adalah variabel pembentukan yang harus dijaga konstan selama proses, peningkatan suhu berpotensi juga dalam variasi ketebalan. Bahan amorphous seperti High Impact Polystyrene (HIPS) dapat dibentuk lebih mudah dari bahan semi kristal karena rentang $\mathrm{Tg}$ yang lebih lebar. Jenis bahan lain yang digunakan untuk kemasan adalah Polymethyl Methacrylate yang lebih dikenal acrylic. Bahan dengan sifat transparan dan ketahanannya dalam bentuk lembaran dengan merek dagang plexiglas, vitroflex, perspex, limacryl, acrylite, acrulplast, altuglas, dan lucite yang sering digunakan dalam berbagai aplikasi seperti lampu kendaraan, monitor, lensa kacamata, dan bahan pelapis pada material pesawat [7]. Produk berbahan Polymethyl Methacrylate banyak digunakan dalam berbagai proses pembentukan produk plastik dengan pengolahan yang umum digunakan pada proses injection molding dan thermoforming dengan menentukan karakteristik dari hasil produk yang diinginkan [7].

Dalam hal mesin vacuum forming, Irwansyah [8] telah melakukan perancangan mesin vacuum forming ukuran maksimal cetakan (Mold) $400 \times 300 \times 150$ (mm) menggunakan software CAD Autodest Inventor Professional 2016. Rentang ketebalan lembaran plastik yang dapat diproses adalah 0.5 sampai $2 \mathrm{~mm}$. Mesin dilengkapi dengan 2 unit pemanas heater masing-masing 250 watt/unit. Kerja vacuum memanfaatkan vacuum cleaner dengan daya tekanan vacuum (max): $20 \mathrm{kPa}(20.000 \mathrm{~Pa})$ dan airflow (max): 26,6 1/s (0,0266 $\mathrm{m}^{\mathrm{a}} /$ detik). Namun demikian, Irwansyah belum merealisasikan rancangan dalam bentuk mesin.

Penelitian ini bertujuan untuk membuat dan menguji kinerja mesin berdasarkan hasil rancangan Irwansyah. Target penelitian adalah mesin vacuum forming sederhana dan murah yang mampu menghasilkan produk kemasan berbahan PMMA dengan geometri dan dimensi presisi. Variasi waktu pemanasan dan waktu vakuum terhadap kualitas produk adalah paramater uji yang menjadi obyek pengamatan. Sebagai pembanding, mesin dengan desain sejenis adalah Formech 508DT dengan harga Rp. 104.062,445 yang telah ada di pasaran. 
2. Metode

2.1 Material

Bahan plastik untuk uji kinerja mesin adalah PMMA merek Sumipex ${ }^{\circledR}$ EX buatan Sumitomo [9]. Sifat bahan PMMA dijelaskan pada tabel 2.1. Tabel 2.2 adalah daftar bahan bahan yang digunakan untuk pembuatan mesin.

Tabel 2.1 Sifat PMMA

\begin{tabular}{lcc}
\hline \multicolumn{1}{c}{ Sifat } & Nilai & Satuan \\
\hline Massa jenis & $1.17-1.2$ & $\mathrm{~g} / \mathrm{cm}^{3}$ \\
Glass transition temperature & 105 & ${ }^{\circ} \mathrm{C}$ \\
(Tg) & $0.2-0.6$ & $\%$ \\
Shrinkage & 68 & $\mathrm{Mpa}$ \\
Tensile strength & 10 & $\mathrm{~g} / 10 \mathrm{~min}$ \\
Melt Flow Index & & \\
\hline
\end{tabular}

Tabel 2.2. Bahan Komponen Mesin

\begin{tabular}{|c|c|c|c|}
\hline No & Komponen & Bahan & Metode Pembuatan \\
\hline 1 & Rangka & Profil L 40x40 & Pemotongan dan pengelasan \\
\hline 2 & Tuas & Besi beton $\phi 16$ & Pemotongan dan bending \\
\hline 3 & Vacuum Chamber & $\begin{array}{l}\text { Stainless steel tebal } 3 \\
\text { mm dan baja ASTM } \\
\text { A529 }\end{array}$ & $\begin{array}{l}\text { Pemotongan, pengelasan, } \\
\text { frais dan bor }\end{array}$ \\
\hline 4 & Mold & Kayu jati & Pemotongan dan frais \\
\hline 5 & Clamp & Besi strip 5 mm & $\begin{array}{l}\text { Pemotongan, pengelasan } \\
\text { dan frais }\end{array}$ \\
\hline 6 & Kotak pemanas & $\begin{array}{l}\text { Plat baja, plat } \\
\text { alumunium, heater }\end{array}$ & $\begin{array}{l}\text { Pemotongan, pengelasan } \\
\text { dan frais }\end{array}$ \\
\hline 7 & Cover & Plat baja ASTM A529 & $\begin{array}{l}\text { Pemotongan, bending, spot } \\
\text { welding }\end{array}$ \\
\hline
\end{tabular}

\subsection{Alur Pembuatan}

Dalam pembuatan mesin vacuum forming terdapat beberapa tahapan, mulai dari persiapan, pembuatan dan pengujian hasil produk yang dilakukan. Diagram alir proses pembuatan mesin vacuum forming ditunjukkan pada gambar 2.1.

Komponen mesin dibuat berdasarkan rancangan yang telah ada. Profil rangka dipotong sesuai ukuran dan disambung dengan pengelasan. Tahap berikutnya adalah membuat bagian tuas, vacuum chamber, pencekam lembaran plastik (clamp), kotak pemanas serta cover, menggunakan mesin perkakas seperti: bubut, frais dan bor. Semua bagian dirakit sesuai dengan tuntutan rancangan. Uji coba mesin dilakukan dengan variasi parameter waktu pemanasan, waktu vakum dan suhu pemanasan. Indikator kualitas adalah bentuk produk yang optimal terutama radius sudut sekecil mungkin. 

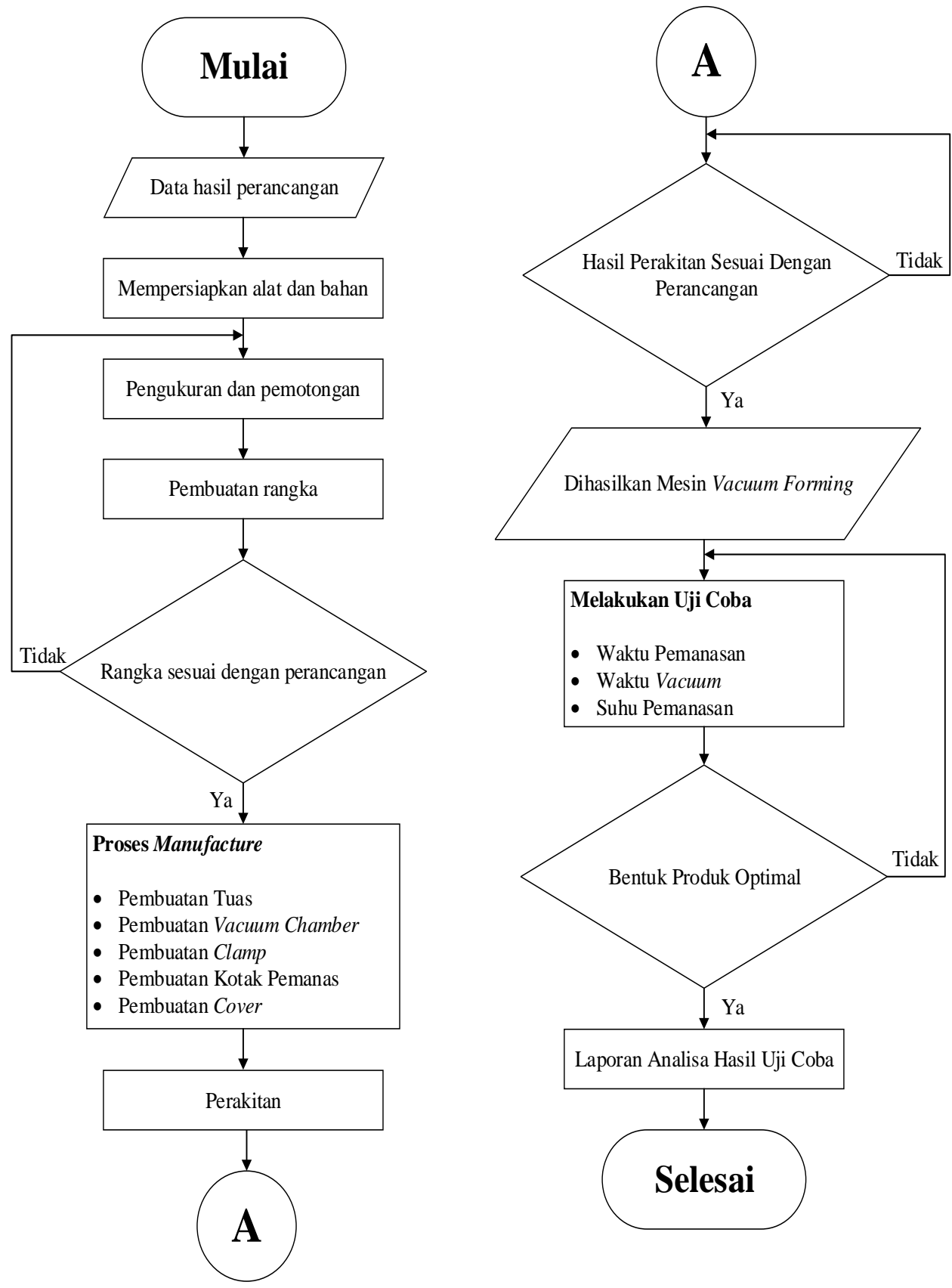

Gambar 2.1 Diagram alir proses pembuatan mesin vacuum forming

\subsection{Mold (Cetakan)}

Menurut Ghani dkk [10], profil cetakan mempengaruhi mampu bentuk yang terjadi pada plastik. Pada profil yang membulat (tidak ekstrem) plastik lebih mudah dibentuk dibandingkan dengan bentuk profil yang memiliki lekukan-lekukan yang tajam (bentuknya ekstrem). Pada tekanan yang rendah pun apabila cetakan memiliki bentuk yang tidak ekstem plastik dapat mampu terbentuk terhadap cetakan. Cetakan bentuk persegi sebagai acuan untuk mengetahui kinerja dari mesin vacuum forming. Bahan cetakan menggunakan kayu jati memiliki ukuran panjang $140 \mathrm{~mm}$, lebar, $210 \mathrm{~mm}$ dan tinggi $15 \mathrm{~mm}$. Dimensi cetakan ditunjukkan pada gambar 2.2. 

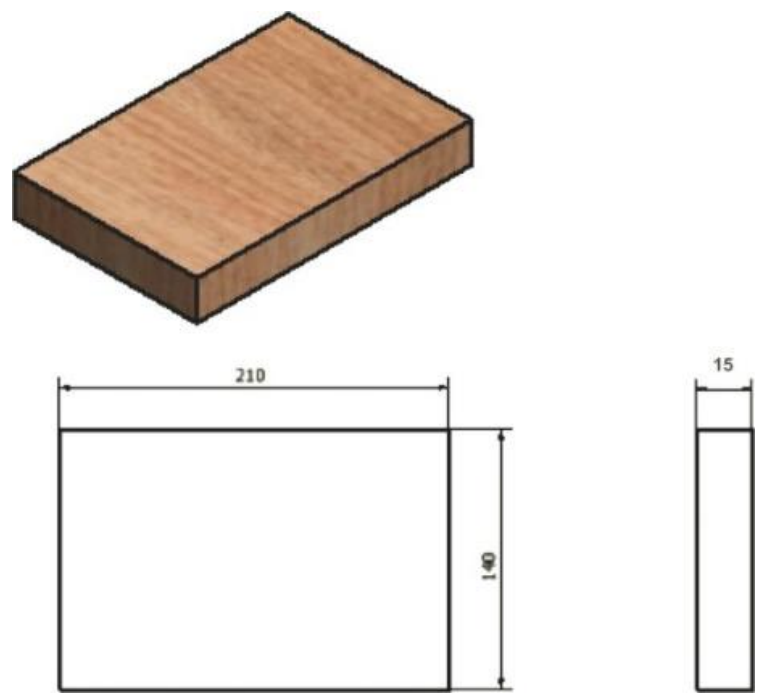

Gambar 2.2 Cetakan pengujian mesin vacuum forming

\section{Hasil dan Pembahasan}

\subsection{Mesin dan Spesifikasi}

Hasil manufaktur mesin dan bagian-bagian utamanya ditunjukkan pada Gambar 3.1. Mesin ini memiliki spesifikasi seperti dijelaskan pada tabel 3.1, spesifikasi tersebut dibandingkan dengan mesin pabrikan sejenis yaitu Formech 508DT buatan Inggris [11]. Sedangkan prosedur pengoperasian dipaparkan secara skematis pada gambar 3.2.

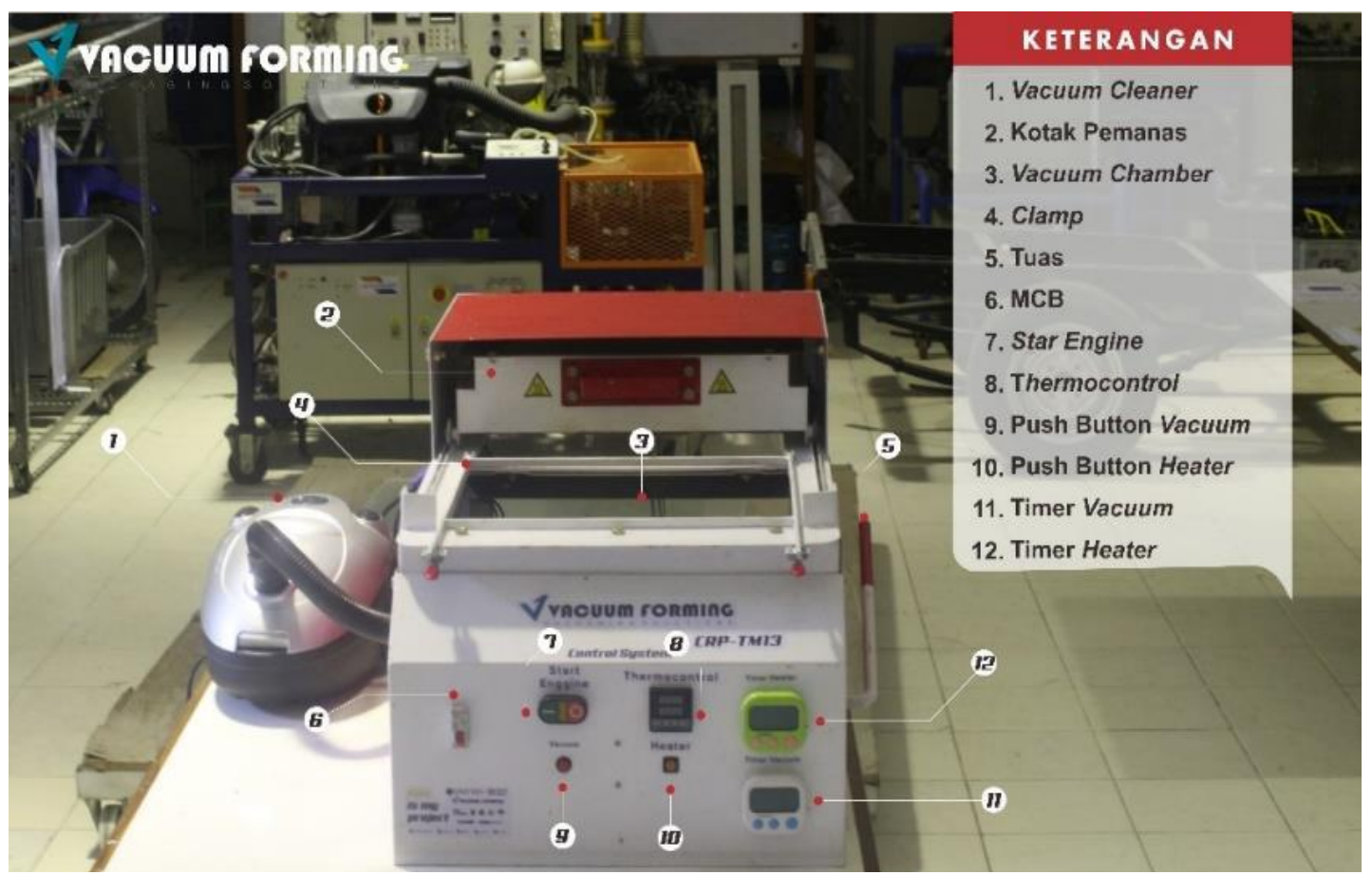

Gambar 3.1 Hasil manufaktur mesin vacuum forming 
Tabel 3.1. Spesifikasi Mesin

\begin{tabular}{lcc}
\hline \multicolumn{1}{c}{ Spesifikasi } & Hasil Riset & Mesin Pabrikan \\
\hline Model Mesin & CRP - TM 13 & Formech 508DT \\
Dimensi Mesin (P x L x T, mm) & $562 \times 880 \times 496$ & $720 \times 1394 \times 538$ \\
Dimensi lembaran plastik (P x L, & $420 \times 320$ & $508 \times 457$ \\
dalam mm) & 220 & 220 \\
Tegangan (volt) & 1750 & 3200 \\
Konsumsi Daya (watt) & 12 & \\
Vacuum pressure (kPa) & Plate & Quartz \\
Jenis heater & $9.247 .000,-$ & $104.062 .445,-$ \\
Harga (Rp) & &
\end{tabular}

\subsection{Cycle Time Proses}

Cycle time proses sebagai salah satu parameter dalam menentukan waktu selama proses pengerjaan mesin vacuum forming untuk menghasilkan suatu produk menggunakan lembaran plastik polymethyl methacrylate dengan tebal $0.20 \mathrm{~mm}$. Tabel 3.2 adalah contoh data waktu siklus kerja secara total yang diperoleh dari observasi proses. Parameter yang membentuk cycle time awal adalah tahap menyalakan mesin, pemasangan cetakan, pemasangan lembaran plastik, waktu pemanasan dan waktu vacuum, dan pelepasan produk. Untuk proses selanjutnya, tahap menyalakan mesin dan pemasangan cetakan dapat dihilangkan dari unsur perhitungan waktu, sehingga waktu siklus untuk variasi waktu pemanasan 25 detik dan waktu vakum 15 detik adalah 49 detik.

Tabel 3.2 Cycle time proses

\begin{tabular}{lc}
\hline \multicolumn{1}{c}{ Parameter } & Waktu (detik) \\
\hline Menyalakan mesin & 2 \\
Pemasangan mold (cetakan) & 4 \\
Pemasangan lembaran plastik & 4 \\
Waktu pemanasan lembaran plastik & 25 \\
Waktu vacuum & 15 \\
Melepaskan produk & 5 \\
\hline & Cycle time proses
\end{tabular}

\subsection{Prosedur Pengoperasian}

Prosedur pengoperasian mesin vacuum forming dengan memperhatikan langkahlangkah sebagai berikut (lihat gambar 3.2):

a. Persiapkan lembaran plastik dan cetakan yang akan digunakan, nyalakan start engine dengan menekan tombol $O N$ dan nyalakan tombol $O N$ kotak pemanas.

b. Masukan mold pada bagian atas vacuum chamber.

c. Masukan lembaran plastik pada ruang cetakan.

d. Turunkan clamp kemudian menekan toggle clamp sampai lembaran plastik terpasang dengan baik

e. Ketika kotak pemanas sudah mencapai suhu yang telah ditentukan kemudian menarik kotak pemanas sampai menutupi lembaran plastik. Tekan tombol timer heater yang sudah di setting terlebih dahulu. Setelah timer berbunyi, kembalikan kotak pemanas dengan mendorong ke posisi semula.

f. Nyalakan tombol ON vacuum. Tekan tombol timer vacuum yang sudah di setting terlebih dahulu. Tarik tuas keatas sampai lembaran plastik sesuai dengan bentuk dari cetakan kemudian menekan tombol OFF vacuum. Turunkan tuas kebawah

g. Lepaskan produk dari cetakan 

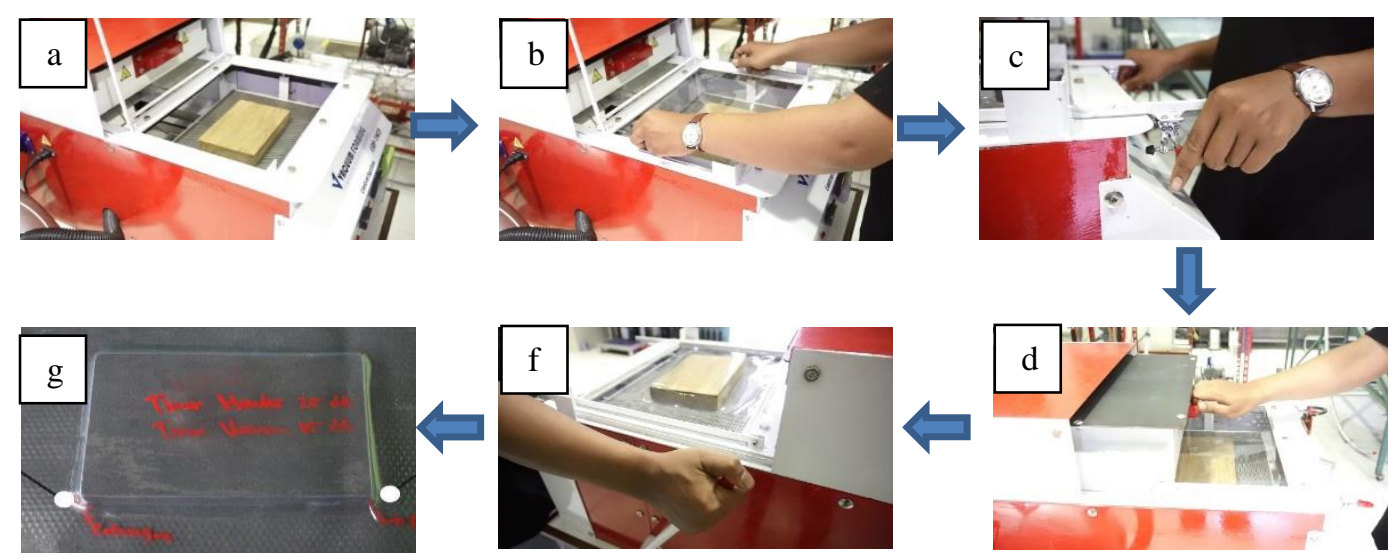

Gambar 3.2 Urutan pengoperasian mesin

\subsection{Pengujian}

Pengujian dilakukan untuk mengetahui hasil kinerja mesin vacuum forming dengan melakukan pengujian secara bertahap menggunakan suhu pemanas sesuai Tg dari PMMA yaitu $105^{\circ} \mathrm{C}$. Dalam pengujian ini digunakan variasi waktu pemanasan 15 detik, 20 detik dan 25 detik dan waktu vacuum masing-masing selama 5 detik, 10 detik dan 15 detik.

\subsubsection{Hasil Pengujian}

Pengujian lembaran plastik polymethyl methacrylate berukuran $420 \mathrm{~mm} \times 320 \mathrm{~mm} \times$ dengan tebal $0.20 \mathrm{~mm}$ menggunakan ukuran cetakan $140 \mathrm{~mm} \times 210 \mathrm{~mm} \times 15 \mathrm{~mm}$ dengan daya hisap vacuum clener maksimal $12 \mathrm{kPa}$. Hasil pengujian diamati kualitasnya secara visual dan pengukuran linear pada ukuran panjang, lebar, tebal dan radius sudutnya. Tabel 3.2 menunjukkan hasil pengujian pada beberapa variasi parameter waktu.

Tabel 3.2 Hasil pengujian mesin vacuum forming

\begin{tabular}{|c|c|c|c|c|}
\hline No & $\begin{array}{c}\text { Waktu } \\
\text { Pemanasan } \\
\text { (dt) }\end{array}$ & $\begin{array}{l}\text { Waktu } \\
\text { Vacuum } \\
\text { (dt) }\end{array}$ & Hasil Pengujian & Keterangan \\
\hline
\end{tabular}

1

15

2

20

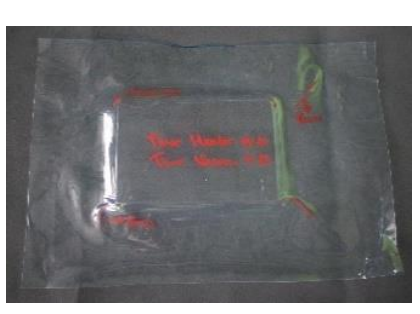

Hasil cetakan terdapat cekungan dan garis dengan daya rekat kurang baik. 


No $\begin{gathered}\text { Waktu } \\ \begin{array}{c}\text { Wemanasan } \\ \text { (dt) }\end{array}\end{gathered} \begin{gathered}\text { Vacuum } \\ \text { (dt) }\end{gathered} \quad$ Hasil Pengujian $\quad$ Keterangan

\begin{tabular}{lcll}
$\begin{array}{c}\text { manasan } \\
(\mathrm{dt})\end{array}$ & $\begin{array}{c}\text { Vacuum } \\
(\mathrm{dt})\end{array}$ & Hasil Pengujian & \multicolumn{1}{c}{ Keterangan } \\
& & \\
25 & 15 & $\begin{array}{l}\text { Hasil cetakan } \\
\text { menyerupai bentuk } \\
\text { dengan cekungan dan } \\
\text { garis. }\end{array}$ \\
& &
\end{tabular}

Dari hasil di atas dapat dinyatakan bahwa produk dengan bentuk dan ukuran terbaik diperoleh pada penyetelan paramater temperatur pemanas $105^{\circ} \mathrm{C}$ dengan daya hisap maksimal $12 \mathrm{kPa}$, waktu pemanasan 25 detik dan waktu vakum 15 detik. Waktu pemanasan di bawah 25 detik belum mampu memberikan efek pelunakan secara merata terhadap permukaan lembaran plastik. Sedangkan waktu vakum yang terlalu singkat belum mampu menghisap secara penuh udara diantara lembaran dan cetakan sehingga radius dan dimensi produk tidak optimal. Namun demikian, dalam proses di atas masih terdapat beberapa kecacatan berupa cekungan dan garis pada produk, hal tersebut diasumsikan terjadi akibat vacuum pressure yang tinggi. Penelitian lebih lanjut perlu dilakukan untuk mengatasi fenomena ini. Percobaan juga dilakukan dengan waktu pemanasan dan vakum yang lebih tinggi namun tidak memberikan pengaruh signifikan pada kualitas akhir produk.

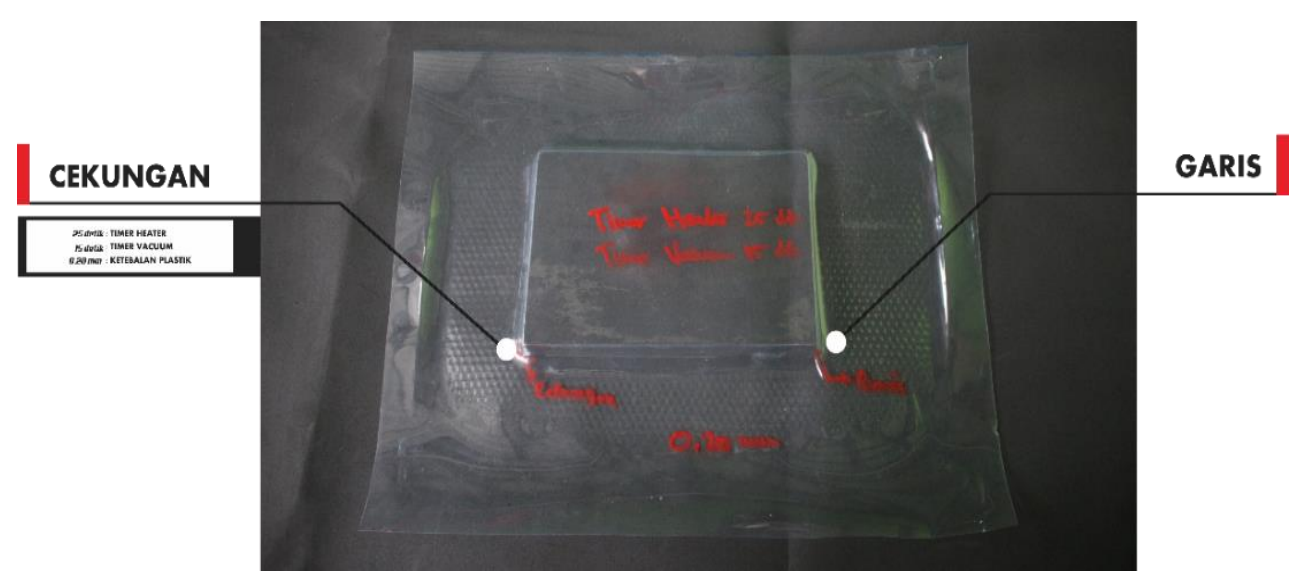

Gambar 3.3 Hasil produk mesin vacuum forming

\section{Kesimpulan}

Mesin vacuum forming dengan biaya pembuatan yang ekonomis dan fungsi yang memadai telah berhasil dibuat dalam penelitian ini. Biaya pembuatan mesin ini hanya Rp. 9.247.000 jauh lebih murah dibandingkan dengan mesin sejenis yang ada di pasaran yaitu type Formech 508DT dengan harga jual Rp. 104.062,445. Uji kinerja menunjukkan bahwa waktu pemanasan dan waktu vakum sangat mempengaruhi kualitas bentuk dari kemasan yang dihasilkan. Hasil terbaik diperoleh dengan variasi waktu pemanasan 25 detik, waktu vakum 15 detik dan suhu pemanas $105^{\circ} \mathrm{C}$. Untuk penelitian lebih lanjut diperlukan pengamatan pengaruh vacuum pressure terhadap kecacatan produk. 


\section{Daftar Pustaka}

[1] S. Julianti, The Art of Packaging: Mengenal Metode, Teknik, \& Strategi Pengemasan Produk untuk Branding. Jakarta: Gramedia Pustaka Utama, 2014.

[2] B. I. Hussain and M. Safiulla, "Comparative study of cooling systems for vacuum forming tool," Mater. Today Proc., vol. 5, no. 1, pp. 30-36, 2018.

[3] S. B. Baliram, D. Rushikesh, Dnyaneshwar, U. A. Jagannath, S. A. Bhausaheb, and B. P. Subhash, "Plan And Development Of Vaccum Forming Machine And Die," Int. Res. J. Eng. Technol., vol. 5, no. 2, pp. 497-500, 2018.

[4] A. Nuari, "Analisis Laju Aliran Panas Pada Proses Thermoforming Blister Packing Mesin Pam-Pac Bp-102 Dengan 2 Desain," J. Tek. Mesin, vol. 06, no. 3, pp. 207-214, 2017.

[5] B. Buffel and F. Desplentere, "A combined experimental and numerical study on pulsed heating of thermoplastic sheets in thermoforming A Combined Experimental And Numerical Study On Pulsed Heating Of Thermoplastic Sheets In Thermoforming," in AIP Conference Proceedings 2139, 2019, vol. 050001, no. August, pp. 1-5.

[6] D. Mckelvey and G. Menary, "Thermoforming of HDPE," in The 20th International ESAFORM Conference on Material Forming, 2017, vol. 060006, pp. 1-6.

[7] E. Pawar, "A Review Article on Acrylic PMMA," IOSR J. Mech. Civ. Eng., vol. 13, no. 2, pp. 1-4, 2016.

[8] D. Irwansyah, "Perancangan Mesin Vacuum Forming Untuk Material Plastik Polystyrene ( Ps ) Dengan Ukuran Maksimal Cetakan," J. Mater. dan Proses Manufaktur, vol. 1, no. 2, pp. 87-95, 2017.

[9] C. Sumitomo, "SUMIPEX ® EX," 2020.

[10] A. Ghani, E. Yohana, and D. B. Wibowo, "Mampu Bentuk Plastik Pada Proses Vacuum Forming Dengan Variasi," J. Tek. Mesin, vol. 2, no. 2, pp. 120-128, 2014.

[11] Formech, "Formech 508DT," 2004. 